\title{
1 Facilitative effects of social partners on Java sparrow activity
}

2

Juan Zhang ${ }^{\mathrm{a}}$, Andrew J. King ${ }^{\text {b, c }}$, Ines Fürtbauer ${ }^{\text {b, c }}$, Yan-Wen Wang ${ }^{\text {a }}$, Ya-Qi He ${ }^{\text {a }}$, Zhi-Wei Zhang ${ }^{\text {a }}$, Dong-Mei Wan ${ }^{\text {a }}$, Jiang-Xia Yin ${ }^{\text {a, * }}$

${ }^{a}$ School of Life Sciences, Liaoning University, Shenyang, Liaoning, China

${ }^{\mathrm{b}}$ Department of Biosciences, College of Science, Swansea University, Swansea, U.K.

${ }^{\mathrm{c}}$ Institute for Communities and Wildlife in Africa, Department of Biological Sciences, University of Cape Town, Cape Town, South Africa

* Author for correspondence:

Dr. Jiang-Xia Yin.

School of Life Sciences, Liaoning University, 110036 Shenyang, Liaoning, China

E-mail address: xia0615@126.com

Declarations of interest: none

\begin{abstract}
Group-living animals can affect each other's behaviour, causing changes in the rate or type of behaviours performed (social facilitation), or convergence in behaviour to that displayed by the majority of neighbours (social conformity). Facilitation and conformity effects can act to reduce direct competition and/or enable social coordination, and the degree to which individuals can affect each other's behaviour can depend upon the identities and traits of those interacting. To investigate the effect of social partners on individual behaviour, we studied the activity of Java sparrows (Lonchura oryzivora) in three contexts (alone, in the presence of three males, or in the presence of three females) and in two conditions (novel environment and novel object tests). A significant proportion of variation in bird activity across trials was attributed to variation among individuals, indicating a personality trait. However, activity varied systematically according to whether birds were tested alone or in the presence of companions. We found that irrespective of the focal bird's sex, individuals were more active in a social context compared to when alone, and this effect was greatest when focal birds were in the presence of male companions. Overall, our findings demonstrate facilitative effects of social partners on Java sparrow activity, and the magnitude of this effect depends on the sex of companions. These results therefore support the hypothesis that social isolation causes behavioural inhibition (which may be caused by increased perception of risk), and future studies should carefully assess the ecological and evolutionary consequences for the emergence of social facilitation, inhibition or conformity across different species and contexts.
\end{abstract}

Key words: activity, Lonchura oryzivora, personality, sex difference, social context 


\section{Introduction}

Consistent individual differences have been described in a wide variety of species and taxa (see Gosling, 2001; Wolf \& Weissing, 2012; for reviews). Such inter-individual differences in behaviour can affect how individuals cope with environmental variation (e.g. Wolf \& Weissing, 2012) and ultimately determine individual survival and reproductive output (e.g. Smith \& Blumstein, 2008). For example, a meta-analysis of published animal personality studies has found 'bolder' males tend to have higher reproductive success than 'shyer' males, but at a greater cost of a shorter life span (Smith \& Blumstein, 2008). Consistent inter-individual differences in behaviour can therefore have important consequences for species ecology and evolution (Dall, Houston, \& McNamara, 2004; Sih, Bell, Johnson, \& Ziemba, 2004), impacting space and habitat use (e.g. Duckworth, 2006), disease and information transmission dynamics (Krause, James, \& Croft, 2010), species interactions (e.g. Schreiber, Bürger, \& Bolnick, 2011), and community structure (e.g. Post, Palkovacs, Schielke, \& Dodson, 2008).

Animal personality can be studied by observer rating (Itoh, 2002) or by coding of behaviour (Watters \& Powell, 2011). Observer rating is a relatively subjective measure that relies on the impression of animal made by experience; in contrast, coding behaviour is a more objective evaluation technique that directly observes and records animal behaviour (Watters \& Powell, 2011) that can indicate presence of personality traits (see Carter, Feeney, Marshall, Cowlishaw, \& Heinsohn, 2013; for reviews). For example, novel environment tests are often used to measure individual's exploration-avoidance and activity.

However, a growing body of evidence suggests that the expression of individual personality can differ depending on whether individuals are on their own or in the presence of companions (Webster \& Ward, 2011). For example, social birds such as common ravens (Corvus corax) and carrion crows (Corvus corone, Corvus cornix) interact more with novel objects in a social context (Miller, Bugnyar, Pölzl, \& Schwab, 2015), but common ravens are quicker to approach novel objects when tested alone (Stöwe, Bugnyar, Heinrich, \& Kotrschal, 2006). Similarly, house sparrows (Passer domesticus) are more active in a social context (Tuliozi, Fracasso, Hoi, \& Griggio, 2018), but zebra finches (Taeniopygia guttata) are bolder in a foraging experiment when alone compared to when in a flock (Kerman, Miller, \& Sewall, 2018).

How individuals affect each other's behaviour may also depend upon the identities of those interacting (conformity). Experiments with Gouldian finch (Erythrura gouldiae), for instance, show that birds adjusted their behaviour according to the personality of their social partner: where birds were paired with a more exploratory or more risk-taking partner, they themselves became more exploratory or more risk-taking than when they were tested alone, and vice versa (King, Williams, \& Mettke-Hofmann, 2015). Despite growing evidence for specific individuals or behavioural types can have moderating effects upon others personality across species and contexts (e.g. Webster \& Ward, 2011; King, Williams, \& Mettke-Hofmann, 2015; Fürtbauer \& Fry, 2018), if and how adjustments in behaviour differ according to the 
sex of conspecifics is not well understood, but may be important for several reasons. For example, males and females can differ in their specific personality traits (e.g. male house sparrows have shorter latencies to forage than females: Tuliozi, Fracasso, Hoi, \& Griggio, 2018) and personality traits can be an indicator for individual quality (e.g. Zann, 1996; Schuett \& Dall, 2009). Therefore, any change in individuals' rate or type of behaviour when with others (social facilitation), or convergence in behaviour to that displayed by the majority of neighbours (social conformity) may differ according to the sexes of interacting individuals (Schuett, Dall, \& Royle, 2011; David, Pinxten, Martens, \& Eens, 2015).

We sought to investigate the effect of same- or opposite-sex social partners on the expression of individual behaviour in the Java sparrow (Lonchura oryzivora). The Java sparrow is a small, highly social, passerine bird species (Islam, 1997) resident in Java and Indonesia which feeds mainly on grain and other seeds (Islam, 1997) and displays sexual dimorphism and elaborate courtship (Soma \& Iwama, 2017). To investigate the potential moderating effects of conspecifics upon Java sparrow activity, we measured the behaviour of birds in three contexts (alone, in the presence of three females, or in the presence of three males) and two conditions (novel environment and novel object tests). This allowed us to test if and how social companion presence and sex may influence activity levels of focal birds when repeatedly tested in behavioural assays in different contexts that are commonly used in personality researches (Toms, Echevarria, \& Jouandot, 2010; Carter, Feeney, Marshall, Cowlishaw, \& Heinsohn, 2013; Perals, Griffin, Bartomeus, \& Sol, 2017; Huang, Kerman, Sieving, \& Mary, 2016). First, to confirm that our measure of activity represents a personality trait, we tested for within-individual consistency and among-individual differences in activity across all trials (Dingemanse \& Dochtermann, 2013; Fürtbauer, Pond, Heistermann, \& King, 2015). Next, if social isolation causes behavioural inhibition due to increased perception of risk (Krause \& Ruxton, 2002; Webster \& Ward, 2011), we expected that focal birds should systematically alter their activity levels, and tested whether birds become more active in the presence of companions, compared to when alone. Finally, we tested whether birds would show greater changes in activity in the presence of the opposite-sex companions compared to same-sex companions due to potentially greater between-sex differences in activity (Ruckstuhl, 1998; Ruckstuhl \& Kokko, 2002) and enhanced social facilitation effects related to sexual behaviour and courtship between the sexes (e.g. Evans \& Marler, 1994).

\section{Methods}

\section{Ethical Note}

All procedures involving animals were carried out in accordance with the Policy on the Care and Use of Animals, approved by the Ethical Committee, Center of Zoological Evolution and Systematic Zoological Museum of China, School of Life Sciences, Liaoning University (EC-LNU 20170150). We adhered to the ASAB/ABS Guidelines for the use of animals. Birds were checked daily for health and injuries and none were observed. 


\section{Study Species and Housing}

Java sparrows were obtained from a registered pet shop in Shenyang, Liaoning, China in March 2018. All birds were bred in farms in Dalian, Liaoning, and were kept in family groups (cage size $31 \times 52 \times 41 \mathrm{~cm})$. After being fledging $(15-20$ days after hatched), birds were transported to pet shops and kept singly (cage size $25 \times 25 \times 25$ $\mathrm{cm})$. Study subjects were purchased at 20-25 days after hatching and were housed singly (cage size $35 \times 30 \times 25 \mathrm{~cm}$ ) in the same keeping room for several months before testing in the laboratory (see below). Birds could see and hear each other in the keeping room but had no physical contact. Birds had full-spectrum light on a 14:10 h light:dark cycle, and the temperature was controlled at $25{ }^{\circ} \mathrm{C}$. Each housing cage contained one feeder, one drinker, two perches, and a nest-box. Birds were fed millet seed, grit, fresh vegetables and water ad libitum. Birds were checked daily for health and injuries.

\section{Behavioural Trials}

We conducted behavioural trials with $N=13$ females and $N=25$ males in a separate test laboratory. Trials were undertaken during the morning, within $5 \mathrm{~h}$ of sunrise, and on each test day between 10-20 focal birds were observed. Birds underwent behavioural trials twice, three weeks apart (Mainwaring, Beal, \& Hartley, 2011). During the first test day birds were observed in the novel environment test, and during the second day birds were observed in the novel object test. During each test day, focal individuals were observed in three contexts (alone, in the presence of three females, or in the presence of three males). The order of the three contexts was randomized to control for order effects. Focal bird testing order was also randomized. On each test day, three male and three female birds were randomly selected from $N=$ 44 birds housed in the same keeping room for use as companion birds in social context trials. The companion birds were placed in a space separated from the focal bird by wire mesh. Thus, companion birds and focal birds had visual and auditory contact, but no physical contact. Companion birds were not used as focal birds and had no prior physical interactions with focal birds. Details of the set-up used in novel environment and novel object tests are given below.

\section{Novel environment}

We used an experimental aviary $(60 \times 43 \times 40 \mathrm{~cm})$ with five perches with different lengths and heights which were randomly positioned for each trial. The aviary was divided into a small introductory space, a test space, and a companion space (Fig. 1a). Both the test space and the companion space had a feeder and a drinker. The focal bird was placed in the introductory space with the sliding door open to freely enter the test space. The sliding door was closed after the bird entered the test space; this was taken as the start time for the trial.

\section{Novel object}

For novel object tests we used the same experimental aviary $(60 \times 43 \times 40 \mathrm{~cm})$ as for the novel environment test, but provided two perches of same length and height, and a 
feeder and a drinker placed on the ground between the two perches (Fig. 1b). An orange doll $(13 \times 7 \times 3 \mathrm{~cm})$ was fixed on one of the perches as the novel object. We chose to use the same novel object in all three contexts (alone, in the presence of three female companions, in the presence of three male companions) since previous studies show the colour, size and structure of novel objects can have large differences on bird behaviour (Wells, 2009; Mastrota \& Mench, 1995; Huber-Eicher \& Wechsler, 1998; McKenna, Sharifi, \& Gerken, 2019) and our goal was to examine the effect of social context on behaviour rather than response to novelty per se. Neither the companion birds nor the focal birds were exposed to the novel environment or novel object prior to testing.
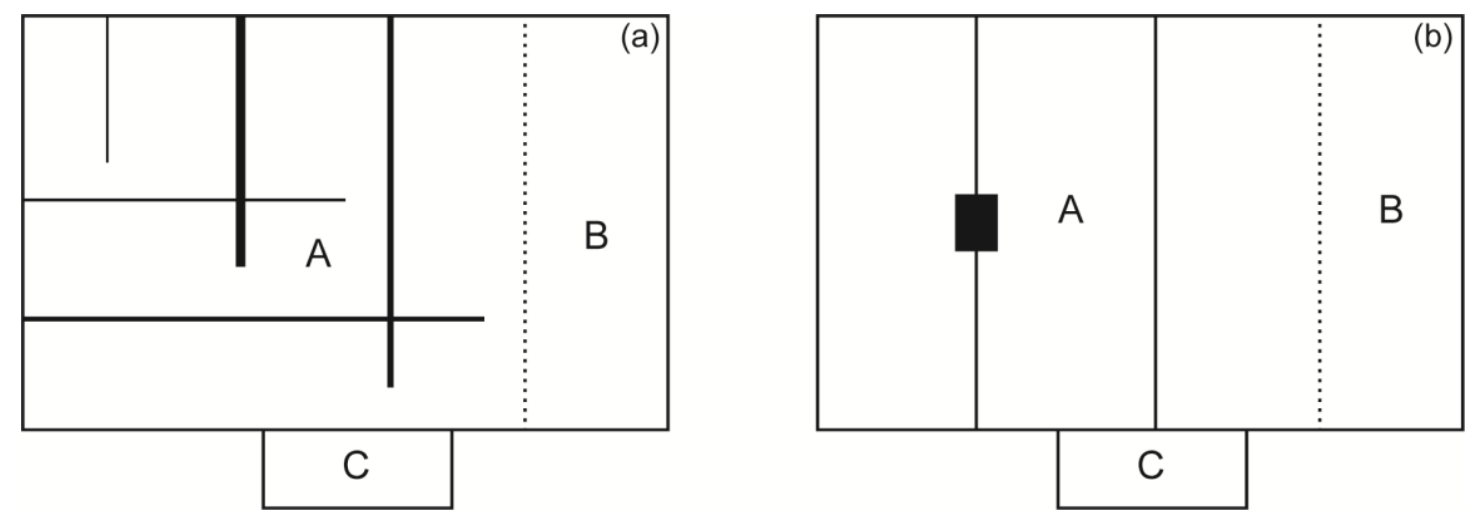

Figure 1. Schematic diagram of (a) novel environment test aviary and (b) novel object test aviary. The dashed line represents a wire mesh, section A, B and C represent the test space, companion space, and introductory space, respectively. In the novel environment aviary, the solid lines of different thickness and length represent five perches of different lengths and heights. In the novel object aviary, the two solid lines represent perches and the black square represent the novel object.

\section{Activity measure}

During trials we recorded the total number of flights and hops focal birds made over a 10-minute period as a measure of activity. Recordings were made using an HP F860 video recorder at a distance of $3 \mathrm{~m}$ from the test space while one operator sat in the test laboratory (Naguib et al., 2013). Using video playbacks, we video noted the total number of flights and hops, and all tests and video noting of activity was undertaken by one observer (JZ). Flight was defined as a movement from one perch to another, and hop was the movement from one end of a perch to the other (Dingemanse, Both, Drent, van Oers, \& van Noordwijk, 2002).

\section{Statistical Analyses}

Data on flight and hop counts were $\ln (\mathrm{x}+1)$ transformed for analyses to meet the assumptions of our statistical models. We tested for differences in activity levels in the novel environment and novel object tests (since habituation might have played a role in the activity levels for the latter) using paired-sample $T$-tests, and tested for repeatability of bird activity across trials by calculating average measures intra-class 
correlation coefficients (ICCs) and 95\% confidence intervals (CIs) using SPSS v. 21.0. We used Linear Mixed Models (LMMs) fitted in $\mathrm{R}(\mathrm{R}$ Development Core Team, 2019), package lme4 (Bates, Maechler, Bolker, \& Walker, 2015) to assess whether context (alone, male companions, female companions) and focal bird sex (male, female), predicted variation in activity levels. We tested for an interaction between context and sex in line with our predictions and fitted bird ID as random intercept in our models to control for individual differences and repeated observations. Model fits were checked by visual inspection of quantile-quantile plots of model residuals versus the predictor.

\section{RESULTS}

\section{Repeatability of Activity}

A significant proportion of observed variation in the sample across the six behavioural trials could be attributed to variation among individuals $(\mathrm{ICC}$ (CI) $=0.267$ (0.144-0.430), $F$-test $37,185=3.191, P<0.001)$. Activity levels were similar in the novel environment and novel object tests (Paired-sample $T$-test: alone: $t_{37}=-1.411, P$ $=0.167$; female companions: $t_{37}=-1.332, P=0.191$; male companions: $t_{37}=1.056, P$ $=0.298$ ) suggesting condition did not affect activity.

Table 1. Results from linear mixed models (LMMs) testing the effects of context, focal bird sex, and potential sex*context interaction on focal bird activity in novel environment and novel object trials.

\begin{tabular}{llll}
\hline Model and Effects & $d f$ & $F$-value & $P$ \\
\hline Novel environment & & & \\
$\quad$ Context (alone, female companions, male companions) & 2 & 21.625 & $<0.001$ \\
Sex (male, female) & 1 & 0.588 & 0.448 \\
$\quad$ Sex*Context & 2 & 1.988 & 0.144 \\
Novel object & & & \\
$\quad$ Context (alone, female companions, male companions) & 2 & 9.734 & $<0.001$ \\
Sex (male, female) & 1 & 1.754 & 0.194 \\
Sex*Context & 2 & 0.035 & 0.965 \\
\hline
\end{tabular}

Focal bird activity (x) expressed as $(\ln (\mathrm{x}+1)) . N=38$. Degrees of freedom $(d f), F$-statistic, and $P$-values are given; see main text for results of comparisons within categories.

\section{Activity and Novel Environment}

Bird activity in the novel environment did not differ according to focal bird sex and was significantly greater when focal birds were in the presence of female companions compared to when alone (LMM: Estimate $\pm \mathrm{SE}=0.901 \pm 0.272, t=3.313, P=0.001$; Table 1, Fig. 2) and male companions compared to when alone (LMM: Estimate \pm SE $=1.682 \pm 0.272, t=6.184, P<0.001$; Table 1, Fig. 2). We found no interaction between sex of the focal bird (male, female) and context (alone, female companion, male companion) on activity levels (Table 1, Fig. 2). Given the inter-individual variation in focal bird activity observed, we included bird identity as a random effect 
and this improved model fit (AIC 403.03 versus 398.24; log-likelihood ratio test: $\mathrm{X}_{1}^{2}$ $=6.793, P=0.009$ ).

\section{Activity and Novel Object}

Bird activity when presented with a novel object did not differ according to focal bird sex and was significantly greater when focal birds were in the presence of female companions compared to when alone (LMM: Estimate $\pm \mathrm{SE}=0.747 \pm 0.244, t=$ 3.061, $P=0.003$; Table 1, Fig. 2) and male companions compared to when alone (LMM: Estimate $\pm \mathrm{SE}=1.106 \pm 0.244, t=4.530, P<0.001$; Table 1, Fig. 2). We found no interaction between sex of the focal bird (male, female) and context (alone, female companion, male companion) on activity levels (Table 1, Fig. 2). Given the inter-individual variation in focal bird activity observed, we included bird identity as a random effect and this produced a comparable model (AIC 369.9 versus 364.69; loglikelihood ratio test: $\mathrm{X}_{1}^{2}=6.793, P=0.096$ ).

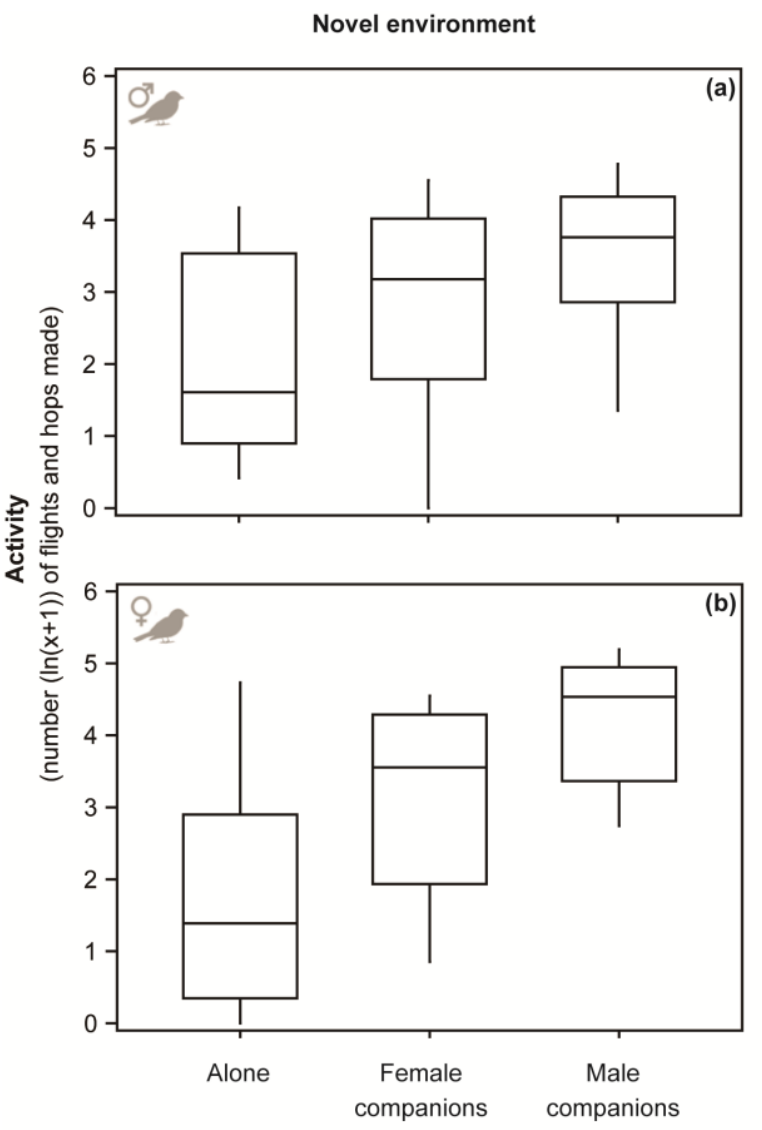

Context
Novel object
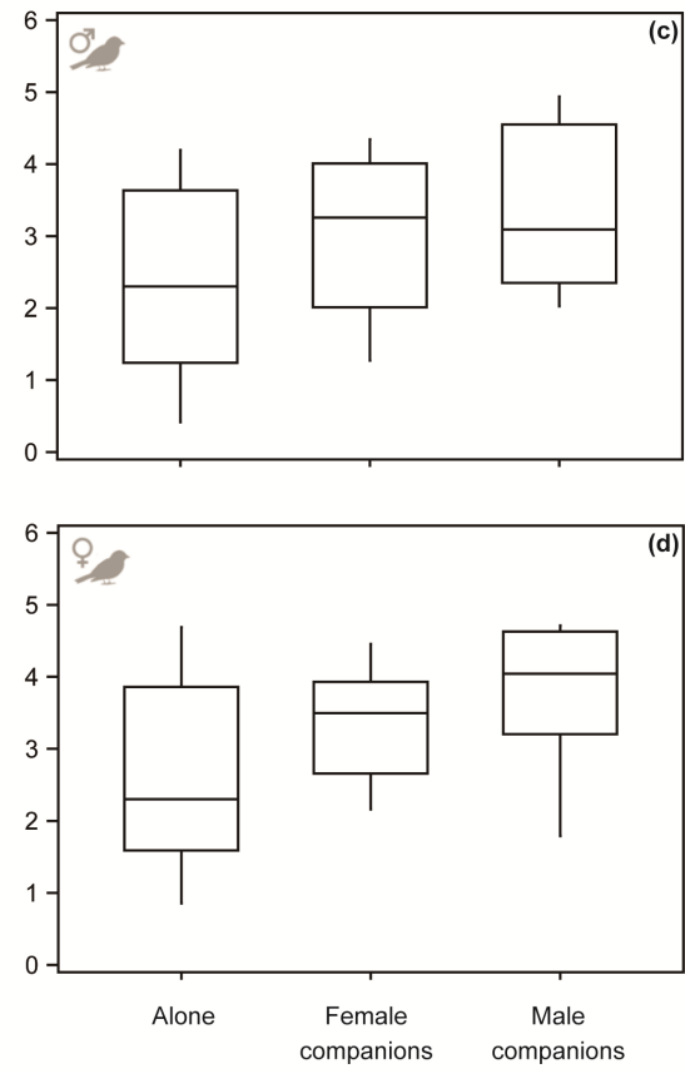

Context

Figure 2. Bird activity (total number of flights and hops) when tested alone, in the presence of three females, or in the presence of three males, in a novel environment (a, b), and when presented with a novel object (c, d), for male (a, c) and female (b, d) focal birds. Counts (x) are expressed as $(\ln (x+1))$. The box plots show the median and 25 th and 75 th percentiles. The whiskers show the lower and upper extremes. 


\section{DISCUSSION}

We examined the activity of Java sparrows in a novel environment and in the presence of a novel object, testing focal birds alone, in the presence of three male companions, or in the presence of three female companions. We found consistent inter-individual differences in activity, no overall sex-differences in behaviour of focal birds across contexts, and higher activity levels in the presence of companions. We discuss each of these main findings in turn.

The within-individual consistency and among-individual differences in activity we observed indicate our activity measure represents a personality trait, in line with previous work (Kluen, Kuhn, Kempenaers, \& Brommer, 2012; Devost, Jones, Cauchoix, Montreuil-Spencer, \& Morand-Ferron, 2016). To limit any possible carryover effects of social conditions prior to behavioural testing on personality (Webster \& Ward, 2011), we housed all birds alone prior to testing. However, this can also affect behavioural expression during tests. For example, Shams et al. (2017) found zebrafish (Danio rerio) show increased locomotion and decreased shoaling during open-field tests following social isolation, and Jolles et al. (2016) found that recent social conditions (either housed solitarily, solitarily part of the time or socially in groups) affected the short-term repeatability of three spined stickleback (Gasterosteus aculeatus) behaviour, with solitary housed individuals showing higher repeatability. We therefore suggest, future work should further investigate the effects of prior social experience upon behavioural expression and consider carefully any order effects.

We did not find support for our prediction that focal birds would show increased activity levels in opposite-sex pairs (Ruckstuhl, 1998; Ruckstuhl \& Kokko, 2002; Evans \& Marler, 1994). We made this prediction on the basis that competitive and cooperative behaviours vary within and between the sexes (Wiley \& Poston, 1996; Wong \& Candolin, 2005; Song et al., 2016) and sex-differences in specific behaviours are common across bird species (e.g. zebra finches: Mainwaring, Beal, \& Hartley, 2011; house sparrows: Ensminger \& Westneat, 2012; Tuliozi, Fracasso, Hoi, \& Griggio, 2018). Instead, we found a similar increase in activity for both male and female focal birds in the presence of the same-sex and opposite-sex companions. This finding could be explained by our use of three companions during tests. In previous work studies have tended to explore changes in the behaviour of individuals when tested alone and in dyads (e.g. van Oers, Klunder, \& Drent, 2005; Fürtbauer \& Fry, 2018; King, Williams, \& Mettke-Hofmann, 2015). Here, our use of a larger number of conspecifics may result in individuals increasing their activity levels to the most active individual or average activity of the group (Webster \& Ward, 2011), and thus potentially mask any specific sex-mediated changes in activity patterns that may be expressed and observable in dyads. Indeed, this is in line with our finding that both males and females tended to show higher activity in the presence of companions.

We also found that both male and female focal birds tended to show greater activity when in the presence of male companions compared to female companions. Islam (1997) found male Java sparrows to be more active than females, and so it is possible 
that three male companions were on average more active than three female companions, and thus elicited greater activity from focal birds. However, we did not find that male focal birds were more active than female focal birds when they were tested singly (or in any of our contexts) suggesting an absence of sex-differences in activity in our study population. However, we cannot rule-out higher male companion activity levels driving the patterns we observed because we have no information about the personalities of companions or their behaviour during trials. We are therefore designing future experiments to investigate this further.

Overall, our results demonstrate that social context can facilitate the expression of individual activity in the Java sparrow, with focal birds being more active in the presence of conspecifics (especially males). These results therefore support the hypothesis that social isolation causes behavioural inhibition (which may be caused by increased perception of risk). In the laboratory, future experiments should investigate (i) the effect of social contexts prior to testing and (ii) the presence of flocks with natural composition (e.g. larger mixed-sex groups) on the activity of individuals to fully understand the behavioural outcomes we report here. In the wild, future studies should assess the ecological relevance of facilitative effects of social partners on Java sparrow activity. For example, it will be useful to investigate how individual personalities affect group activity and if social facilitation provides a behavioural mechanism for altering group phenotypic composition (Farine, Montiglio, $\&$ Spiegel, 2015). Specifically, we would predict that social facilitation of activity could enhance coordination and cohesion of large mobile flocks in the wild, but that there would also be constraints on the degree to which individuals are able to change their behaviours (i.e. their behavioural plasticity). This may result in association by phenotype (here, activity levels) that would decrease individual heterogeneity within groups, and increase it between groups.

\section{Acknowledgements}

We thank the staff of the key laboratory of Animal Resource and Epidemic Disease Prevention in Liaoning Province for assistance with laboratory work. We also thank Animal Behaviour Editor Claudia Wascher, Xiaotao Lü, and two anonymous Referees for improving our manuscript, and Layla King for support. This work was supported by Doctoral Scientific Research Foundation of Liaoning (20170520179), Shenyang Science and Technology Bureau (18-013-0-04), and Liaoning natural fund guidance plan (2019-ZD-0196). Authors declare no conflict of interests.

\section{Author contributions}

JXY, DMW, and JZ designed the experiment. JZ, YWW, YQH, and ZWZ performed the data collection. JZ, AJK and IF conducted the analyses. JZ, JXY, AJK, and IF wrote the manuscript with feedback from all co-authors

\section{References}

Bates, D., Maechler, M., Bolker, B., \& Walker, S. (2015). Fitting linear mixed-effects models using lme4. Journal of Statistical Software, 67, 1-48. 
Carter, A. J., Feeney, W. E., Marshall, H. H., Cowlishaw, G., \& Heinsohn, R. (2013). Animal personality: what are behavioural ecologists measuring? Biological Reviews, 88(2), 465-475.

Dall, S. R., Houston, A. I., \& McNamara, J. M. (2004). The behavioural ecology of personality: consistent individual differences from an adaptive perspective. Ecology Letters, 7(8), 734-739.

David, M., Pinxten, R., Martens, T., \& Eens, M. (2015). Exploration behavior and parental effort in wild great tits: partners matter. Behavioral Ecology and Sociobiology, 69(7), 1085-1095.

Devost, I., Jones, T. B., Cauchoix, M., Montreuil-Spencer, C., \& Morand-Ferron, J. (2016). Personality does not predict social dominance in wild groups of black-capped chickadees. Animal Behaviour, 122, 67-76.

Dingemanse, N. J., Both, C., Drent, P. J., van Oers, K., \& van Noordwijk, A. J. (2002). Repeatability and heritability of exploratory behaviour in great tits from the wild. Animal Behaviour, 64(6), 929-938.

Dingemanse, N. J., \& Dochtermann, N. A. (2013). Quantifying individual variation in behaviour: mixed- effect modelling approaches. Journal of Animal Ecology, 82(1), 39-54.

Duckworth, R. A. (2006). Aggressive behaviour affects selection on morphology by influencing settlement patterns in a passerine bird. Proceedings of the Royal Society B: Biological Sciences, 273(1595), 1789-1795.

Ensminger, A. L., \& Westneat, D. F. (2012). Individual and Sex Differences in Habituation and Neophobia in House Sparrows (Passer domesticus). Ethology, 118(11), 1085-1095.

Evans, C. S., \& Marler, P. (1994). Food calling and audience effects in male chickens, Gallus gallus: their relationships to food availability, courtship and social facilitation. Animal Behaviour, 47(5), 1159-1170.

Farine, D. R., Montiglio, P. O., \& Spiegel, O. (2015). From individuals to groups and back: the evolutionary implications of group phenotypic composition. Trends in Ecology \& Evolution, 30(10), 609-621.

Fürtbauer, I., Pond, A., Heistermann, M., \& King, A. J. (2015). Personality, plasticity and predation: linking endocrine and behavioural reaction norms in stickleback fish. Functional Ecology, 29(7), 931-940.

Fürtbauer, I., \& Fry, A. (2018). Social conformity in solitary crabs, Carcinus maenas, is driven by individual differences in behavioural plasticity. Animal Behaviour, 135, 131-137.

Gosling, S. D. (2001). From mice to men: what can we learn about personality from animal research? Psychological Bulletin, 127(1), 45.

Huang, P., Kerman, K., Sieving, K. E., \& Mary, C. M. S. (2016). Evaluating the novel-environment test for measurement of exploration by bird species. Journal of Ethology, 34(1), 45-51.

Huber-Eicher, B. E. A. T., \& Wechsler B. (1998). The effect of quality and availability of foraging materials on feather pecking in laying hen chicks. Animal Behaviour, 55(4), 861-873.

Islam, K. (1997). Java Sparrow (Padda oryzivora). The Birds of North America, (304), 12.

Itoh, K. (2002). Personality research with non-human primates: Theoretical formulation and methods. Primates, 43(3), 249-261.

Jolles, J. W., Taylor, B. A., \& Manica, A. (2016). Recent social conditions affect boldness repeatability in individual sticklebacks. Animal Behaviour, 112, 139-145.

Kerman, K., Miller, L., \& Sewall, K. (2018). The effect of social context on measures of boldness: Zebra finches (Taeniopygia guttata) are bolder when housed individually. Behavioural 
Processes, 157, 18-23.

King, A. J., Williams, L. J., \& Mettke-Hofmann, C. (2015). The effects of social conformity on Gouldian finch personality. Animal Behaviour, 99, 25-31.

Kluen, E., Kuhn, S., Kempenaers, B., \& Brommer, J. E. (2012). A simple cage test captures intrinsic differences in aspects of personality across individuals in a passerine bird. Animal Behaviour, 84(1), 279.

Krause, J., \& Ruxton, G. D. (2002). Living in groups. Oxford University Press.

Krause, J., James, R., \& Croft, D. P. (2010). Personality in the context of social networks. Philosophical Transactions of the Royal Society B: Biological Sciences, 365(1560), 40994106.

Mainwaring, M. C., Beal, J. L., \& Hartley, I. R. (2011). Zebra finches are bolder in an asocial, rather than social, context. Behavioural Processes, 87(2), 171-175.

Mastrota, N. F., \& Mench, J. A. (1995). Colour avoidance in northern bobwhites: effects of age, sex and previous experience. Animal Behaviour, 50(2), 519-526.

McKenna, L., Sharifi, A. R., \& Gerken, M. (2019). Behavioural and cardiac responses towards different novel objects in juvenile female and male pigs (Sus scrofa). Applied Animal Behaviour Science, 215, 13-20.

Miller, R., Bugnyar, T., Pölzl, K., \& Schwab, C. (2015). Differences in exploration behaviour in common ravens and carrion crows during development and across social context. Behavioral Ecology and Sociobiology, 69(7), 1209-1220.

Naguib, M., van Oers, K., Braakhuis, A., Griffioen, M., de Goede, P., \& Waas, J. R. (2013). Noise annoys: effects of noise on breeding great tits depend on personality but not on noise characteristics. Animal Behaviour, 85(5), 949-956.

Perals, D., Griffin, A. S., Bartomeus, I., \& Sol, D. (2017). Revisiting the open-field test: what does it really tell us about animal personality? Animal Behaviour, 123, 69-79.

Post, D. M., Palkovacs, E. P., Schielke, E. G., \& Dodson, S. I. (2008). Intraspecific variation in a predator affects community structure and cascading trophic interactions. Ecology, 89(7), 2019-2032.

R Development Core Team. (2019). R: A language and environment for statistical computing. Vienna, Austria: R Foundation for Statistical Computing.

Ruckstuhl, K. E. (1998). Foraging behaviour and sexual segregation in bighorn sheep. Animal Behaviour, 56(1), 99-106.

Ruckstuhl, K. E., \& Kokko, H. (2002). Modelling sexual segregation in ungulates: effects of group size, activity budgets and synchrony. Animal Behaviour, 64(6), 909-914.

Schreiber, S. J., Bürger, R., \& Bolnick, D. I. (2011). The community effects of phenotypic and genetic variation within a predator population. Ecology, 92(8), 1582-1593.

Schuett, W., \& Dall, S. R. (2009). Sex differences, social context and personality in zebra finches, Taeniopygia guttata. Animal Behaviour, 77(5), 1041-1050.

Schuett, W., Dall, S. R., \& Royle, N. J. (2011). Pairs of zebra finches with similar 'personalities' make better parents. Animal Behaviour, 81(3), 609-618.

Shams, S., Amlani, S., Buske, C., Chatterjee, D., \& Gerlai, R. (2017). Developmental social isolation affects adult behavior, social interaction, and dopamine metabolite levels in zebrafish. Developmental Psychobiology, 60(1), 43-56.

Sih, A., Bell, A. M., Johnson, J. C., \& Ziemba, R. E. (2004). Behavioral syndromes: an integrative 
overview. The Quarterly Review of Biology, 79(3), 241-277.

Smith, B. R., \& Blumstein, D. T. (2008). Fitness consequences of personality: a meta-analysis. Behavioral Ecology, 19(2), 448-455.

Soma, M., \& Iwama, M. (2017). Mating success follows duet dancing in the Java sparrow. PloS One, 12(3), e 0172655.

Song, Z., Lou, Y., Hu, Y., Deng, Q., Gao, W., \& Zhang, K. (2016). Local resource competition affects sex allocation in a bird: experimental evidence. Animal Behaviour, 121, 157-162.

Stöwe, M., Bugnyar, T., Heinrich, B., \& Kotrschal, K. (2006). Effects of group size on approach to novel objects in ravens (Corvus corax). Ethology, 112(11), 1079-1088.

Toms, C. N., Echevarria, D. J., \& Jouandot, D. J. (2010). A methodological review of personality-related studies in fish: focus on the shy-bold axis of behavior. International Journal of Comparative Psychology, 23(1).

Tuliozi, B., Fracasso, G., Hoi, H., \& Griggio, M. (2018). House sparrows' (Passer domesticus) behaviour in a novel environment is modulated by social context and familiarity in a sex-specific manner. Frontiers in Zoology, 15(1), 16.

van Oers, K., Klunder, M., \& Drent, P. J. (2005). Context dependence of personalities: risk-taking behavior in a social and a nonsocial situation. Behavioral Ecology, 16(4), 716-723.

Watters, J. V., \& Powell, D. M. (2011). Measuring animal personality for use in population management in zoos: suggested methods and rationale. Zoo Biology, 31(1), 1-12.

Webster, M. M., \& Ward, A. J. (2011). Personality and social context. Biological Reviews, 86(4), 759-773.

Wells, D. L. (2009). Sensory stimulation as environmental enrichment for captive animals: a review. Applied Animal Behaviour Science, 118(1-2), 1-11.

Wiley, R. H., \& Poston, J. (1996). Perspective: indirect mate choice, competition for mates, and coevolution of the sexes. Evolution, 50(4), 1371-1381.

Wolf, M., \& Weissing, F. J. (2012). Animal personalities: consequences for ecology and evolution. Trends in Ecology \& Evolution, 27(8), 452-461.

Wong, B. B., \& Candolin, U. (2005). How is female mate choice affected by male competition? Biological Reviews, 80(4), 559-571.

Zann, R. A. (1996). The zebra finch: a synthesis of field and laboratory studies (Vol. 5). Oxford University Press. 